\title{
A RESEARCH ON THE FACTORS AFFECTING CRYPTOCURRENCY INVESTMENTS WITHIN THE GENDER CONTEXT
}

DOI: 10.17261/Pressacademia.2021.1463

JBEF-V.10-ISS.4-2021(4)-p.178-189

\section{Cagla Gul Senkardes ${ }^{1}$, Ozan Akadur ${ }^{2}$}

${ }^{1}$ Istanbul Bilgi University, Department of Engineering and Natural Sciences, Istanbul, Turkey. caglasenkardes@gmail.com , ORCID: 0000-0002-3109-3268

${ }^{2}$ Bahcesehir University, Institute of Social Sciences, Istanbul, Turkey. ozanakadur@hotmail.com , ORCID: 0000-0002-5483-8330

To cite this document

Senkardes, C.G., Akadur, O., (2021). A research on the factors affecting cryptocurrency investments within the gender context. Journal of Business, Economics and Finance (JBEF), 10(4), 178-189.

Permanent link to this document: http://doi.org/10.17261/Pressacademia.2021.1463

Copyright: Published by PressAcademia and limited licensed re-use rights only.

\section{ABSTRACT}

Purpose- Cryptocurrency, which is one of the first products of blockchain technology, is preferred by more and more actors in addition to traditional investment tools. One of the factors over demographic and psychological factors that affect the financial investment decisions of individuals is gender. Although there are many studies in the academic literature on gender-related financial investment decisions, there is no research and data on cryptocurrencies. In this study, the factors affecting cryptocurrency investments are examined within the context of gender.

Methodology- Survey model was used as a quantitative research method. With the computer aided survey research conductd in Turkey, gender-related behavioral and psychological differences in cryptocurrency investments were revealed and the survey findings were discussed over the information obtained from the literature review.

Findings- With this research, it was seen that the gender factor was associated with both psychological and demographic factors. Cryptocurrencies are in the top 5 in men's financial investment instruments portfolio while 32.6 percent of women invest in cryptocurrencies. The level of knowledge about cryptocurrencies, which is effective in investment preferences, is at medium and high level at the rate of 64 percent for men however 60 percent of women have very limited or no knowledge about this investment tool. The first two of the factors that affect cryptocurrency investment decisions which are confidence and volatility also differ in terms of rank and proportion. Age-related cryptocurrency investment preferences do not differ by gender. This study shows that men follow their investments more frequently than women and do not avoid taking risks.

Conclusion- With this research, gender-based main preference differences in cryptocurrency investments are revealed and an important resource is provided in this field, which has limited research, and contributes to the literature. It has been observed that women prefer different investment tools primarily due to lower income and lower level of knowledge about cryptocurrencies. Factors showing similarity based on gender were also found by this research.

Keywords: Cryptocurrencies, blockchain technology, financial ınvestments, female investors, gender JEL Codes: D31, G11, G41, J16

\section{INTRODUCTION}

The real and legal actors in the economy that invest with the unspent portion of their income are called investors. (Usul et al., 2002) Today, investors are examined in two categories as individual and institutional investors, and the subject of this study is individual investors who invest by themselves without outside support. (Yllmaz, 2009) The main reasons for investing in terms of investors can be expressed as protecting their resources, creating an increase in their resources, obtaining a regular income and realizing the benefit they expect from their investments. (Usul et al., 2002). Studies in the field of behavioral finance show that personality traits, socio-economic and demographic conditions, and some psychological and emotional factors affect investors' perceived risk. (Kahyaoğlu, 2011) There are many studies in the academic literature on the gender factor, which is one of the effective factors in investment decisions based on demographic and psychological factors. Many studies have focused on the effect of gender on financial risk taking and it has been revealed that women exhibit less risky behaviours than men. (Fehr-Duda et al., 2006; Anbar \& Eker, 2009; Wang et al., 2011; Uluyol, 2019). Developing technologies affect investment products and the preferences of individual investors. Cryptocurrencies, which is one of the first products of blockchain technology that allows data to be transferred in 
a distributed structure with encryption and timestamping, are digital currencies that can be used without intermediaries. Today more than 10 thousand cryptocurrencies, which started to become widespread with the blockchain technology, has reached a large market volume and became one of the important investment tools. (CoinMarketCap, 2021; CoinGecko, 2021)

In the literature review section of this research, in which the factors affecting cryptocurrency investments are examined in the context of gender, cryptocurrencies, the cryptocurrency market in investment focus, and the factors affecting cryptocurrency investments are examined. In the second part of the study, research findings on the analysis of the factors affecting the decisions of cryptocurrency investors in the context of gender are presented. The findings of the research conducted in the sample of Turkey with 399 participants are discussed through the literature on investment decisions in the context of gender. With this research, it is aimed to contribute to the academic literature, which has very limited resources within the framework of the factors affecting cryptocurrency investments, and investor dynamics that differ in terms of gender.

\section{A GENERAL PERSPECTIVE FOR CRYPTOCURRENCY MARKET}

\subsection{Cryptocurrencies}

Cryptocurrencies entered the literature in 2008 as digital data that can be produced and transferred on blockchain technology. The word blockchain was first used in discussions that started over the article "Bitcoin: A Peer-to-Peer Electronic Cash System" published by an author named Satoshi Nakamoto (2008). Blockchain is a technology that provides a secure, transparent digital transaction ledger that allows data to be recorded and transferred over the internet as timestamped, in a distributed structure, encrypted, and unalterable. (Gül Şenkardeş, 2021) The first cryptocurrency produced after Bitcoin was developed on the Ethereum protocol, which was introduced in 2015. The ready-made software called smart contract, presented with the Ethereum blockchain, whose technical information document called whitepaper was published on November 27, 2013, made it possible to produce different cryptocurrencies on this network. Cryptocurrencies are defined by Güleç et al. (2018) as cryptography based, mathematically encrypted digital currencies that are suitable for use in digital mediums. Cryptology is a science that aims to keep data confidential through encryption and at the same time to protect data integrity (YIImaz, 2007). According to another definition, cryptology is the sum of the methods used to transform a data that is not desired to be read and cannot be understood by other users (Doğan, 2020). Due to the features of the blockchain technology and cryptology on which they are developed, security can be provided without any intermediary or central authority in cryptocurrencies.

Cryptocurrencies are followed by more and more users all over the world. As an indicator of the increase in interest in cryptocurrencies, the increase in searches with the phrase "Cryptocurrency" from Google can be seen as a data. Google search engine is the world's most visited website and search engine according to Similarweb, Semruah and Alexa reports. (Hootsuite, 2021) The increase in worldwide searches for cryptocurrencies on Google between 2009, when the first cryptocurrency was transferred, and 2021, when this article was written, is given in Figure 1. The increase in similar calls made within the scope of Turkey for the same period is given in Figure 2.

Figure 1: Google Search Engine "cryptocurrency" Search (Worldwide)

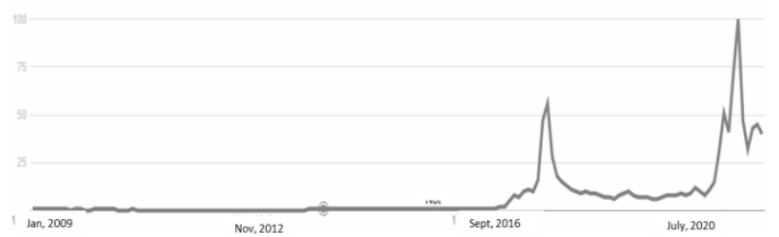

Source: Google Trends, Accessed: 08.10.2021

Figure 2: Google Search Engine "cryptocurrency" Search (Turkey)

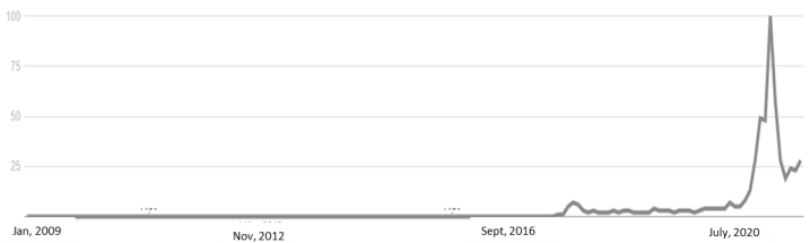

Source: Google Trends, Accessed: 08.10.2021 
It is seen in the figures that the interest in cryptocurrencies has increased globally as well as locally in Turkey since 2016. The reflection of this interest in cryptocurrency investments has started in 2015 and continued with an increasing volume. Global data on the use of cryptocurrencies for different purposes are given in Figure 3 . This chart has been prepared by the authors of this article, based on weekly cryptocurrency market volume forecast data published by Statista (2021), a globally independent research and reporting company, and daily cryptocurrency market cap data shared by CoinMarketCap. Cryptocurrency market cap chart shown in Figure 3 has been prepared by calculating the data for the same period every year as of October 2010.

\section{Figure 3: Cryptocurrency Market Cap}

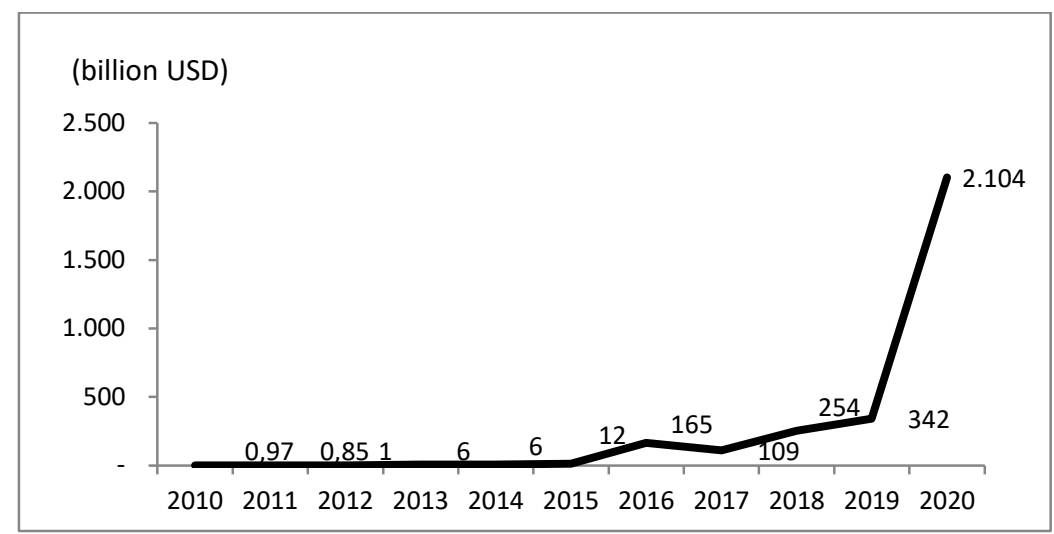

The total trade volume of approximately 10 thousand cryptocurrencies traded on a global scale as of October 2021 is over 2.1 trillion USD. (CoinMarketCap 2021; Coingecko 2021) Detailed information on the cryptocurrency market will be given in the next section, however it is seen that cryptocurrency investments are increasing day by day in line with this data provided by Figure 3. One of the most important debates about cryptocurrencies, which continues to become widespread in a graphic that is rapidly increasing in both interest and usage, is the phenomenon of whether they are money or not. Unlike traditional currencies, cryptocurrencies are not tied to a central authority. The fact that it is not under the control of individuals or institutions is the most distinctive feature that distinguishes cryptocurrencies from traditional currencies. According to Ecom World (2021), it is not essential for something to be a banknote or a coin in order to be considered a currency. In addition, for something to be considered a currency, it must fulfill the functions of exchange, unit of account, and wealth accumulation. (Ülgen, 2010) Today, while there are different opinions about the fact that cryptocurrency, which is not a banknote or a coin type, has these three functions, cryptocurrencies can be used for investment and savings together with traditional money.

\subsection{Cryptocurrency Market}

The market is the name given to the environments where buyers and sellers come together physically, over computers or other mobile devices, to buy or sell. Cryptocurrency market, on the other hand, is the market where cryptocurrencies are bought and sold. In the cryptocurrency markets, uninterrupted transactions can be made 7 days a week and 24 hours a day (Yılmaz and Akkaya, 2020). Manipulative movements or many irrational buying-selling movements can affect the markets. These movements are one of the main reasons for the fluctuations in the market (Güleç and Aktaş 2019). Cryptocurrency market is one of the markets that react most quickly and strongly to hot information. According to the data of CoinMarketCap (2021), which is one of the most comprehensive information platforms about the cryptocurrency market, a total of 12,282 cryptocurrencies are traded on 418 exchanges on October 4, 2021. The market value was 2.11 trillion USD as of the same date. In terms of market cap, the market is dominated by Bitcoin with a 42.5 percent share. Ethereum is the second most valuable cryptocurrency in the market, with a share of 18 percent. According to the data of the same date, over 93 billion US dollars were traded in all exchanges in the last 24 hours. The value of cryptocurrencies can be measured over the amounts reached by their market values and their market shares (Deniz, 2020). As of October 4, 2021, the top 20 cryptocurrencies with the highest market value and their market shares are given in Table 1.

Table 1: Top 20 Cryptocurrencies with the Highest Market Caps and their Market Volumes

\begin{tabular}{llll}
\hline Order & Cryptocurrency & Price (USD) & Market Cap (USD) \\
\hline 1 & Bitcoin & $54,272.73$ & $1,023,489,349,878$ \\
2 & Ethereum & $3,601.23$ & $424,818,311,786$ \\
3 & Cardano & 2.26 & $72,559,411,434$
\end{tabular}




\begin{tabular}{llll}
4 & Binance Coin & 421.26 & $70,915,305,357$ \\
5 & Tether & one & $68,238,973,823$ \\
6 & Ripple & 1.07 & $50,073,832,904$ \\
7 & Wither & 165.78 & $49,743,963,684$ \\
8 & Polkadot & 33.76 & $33,316,915,209$ \\
9 & USD Coins & one & $32,840,941,204$ \\
10 & Dogecoin & 0.24 & $32,224,740,755$ \\
11 & Terra & 44.5 & $17,878,841,984$ \\
12 & Uniswap & 25.41 & $15,560,735,141$ \\
13 & Avalanche & 62.9 & $13,851,740,933$ \\
14 & Binance USD & one & $13,033,693,937$ \\
15 & Litecoin & 180.96 & $12,429,717,095$ \\
16 & Chainlink & 26.92 & $12,288,329,516$ \\
17 & Algorand & 1.93 & $11,844,646,432$ \\
18 & Wrapped Bitcoin & $54,412.78$ & $11,389,461,175$ \\
19 & Bitcoin Cash & 602.69 & $11,361,620,972$ \\
20 & SHIBA INU & 0 & $10,131,125,834$ \\
\hline
\end{tabular}

Source: CoinMarketCap, Accessed: 08.10.2021

The total market value in cryptocurrencies is calculated with the following formula.

(Cryptocurrency Market Cap = Total Number of Cryptocurrencies * Market Price)

According to Deniz (2020), cryptocurrencies can be viewed in three categories according to the size of their market values, namely large, medium and small capital value. Cryptocurrencies with a market value of less than 1 billion USD are in the small capital category according to Deniz's (2020) definition. As of October 2021, there are 12,420 cryptocurrencies in this category. Deniz defined it as the large capitalization value for cryptocurrencies with a market value of 10 billion USD and above from these categories. According to this definition, 20 cryptocurrencies with the largest market capitalization seen in Table 1 fall into the category of large capital. Although market value information does not provide clear and precise information about the direction of the prices of cryptocurrencies, its development over the years guides investment decisions. (Deniz, 2020) The total market size of cryptocurrencies shown in Table 1 is 1.98 trillion USD. The total market capitalization of these cryptocurrencies constitutes 86 percent of the total size of the market.

\section{LITERATURE REVIEW}

The concept of investment, which has given different meanings in the fields of business, economy and finance, is a general and inclusive expression by Özdaş (2009) as "firms or individuals directing and/or evaluating their economic assets with the aim of profit, and depositors depositing their savings in banks, bonds, stocks or gold, real estate, etc. by evaluating it as a purchase of goods and having an income expectation from these investments in the future". Based on this definition, individuals who direct some of their income to investment instruments can be called individual investors. Investments made by individual investors are personal. (YIlmaz, 2009) The main motivation in individual investments is to provide maximum return with minimum risk factor. (Jones, 1999) There are many different investment instruments that can be invested by individual investors. It can be said that the most invested instruments in Turkey are Turkish Lira deposits, foreign currency deposits, precious metals, fixed-income securities and mutual funds, according to the household data from the Central Bank of the Republic of Turkey. (CBRT, 2021) Although there are very limited studies on cryptocurrency investments in the academic literature and research reports, cryptocurrencies have become an important investment tool with a market volume of over 2 million USD, the details of which were shared in the previous section. In their study, Sütçü and Aytekin (2018) examined the miners of Bitcoin and the trade in the context of entrepreneurship. Pelster, Breitmayer, and Hasso (2019) examined the reasons of investment for individual cryptocurrency investors. In the study, the first crypto investments of these investors were examined and it was concluded that the first crypto investments were made with a sense of excitement seeking. In the research conducted by Yilmaz and Hazar (2018), return on cryptocurrency investments, user experience, security, anonymity, security, and accounting were examined as effective factors.

The factors affecting the traditional financial investment decisions of individuals can be basically examined in two parts as demographic and psychological factors. In this research, individual cryptocurrency investments are also discussed according to these factors. 


\subsection{Demographic Factors Affecting Cryptocurrency Investments}

In this section, age, gender, education and income status will be discussed respectively as demographic factors that affect cryptocurrency investments.

\subsubsection{Age}

The risk that can be taken in terms of investment decisions and investment types varies according to the age of the investor. Korniotis and Kumar (2011) examined whether older investors make better investment decisions and showed in their research that older investors have more knowledge and experience in portfolio management, but their investment skill deteriorates with age. Hallahan et al. (2004) found that age and risk tolerance were inversely correlated with each other. Accordingly, as the age of the individuals increases, they stay away from risky behaviors. Age emerges as an important factor affecting the decision-making mechanism. Since the volatility of crypto money prices is high, they can be considered as a riskier investment tool when compared to other investment instruments. One of the most important factors affecting the prices of cryptocurrencies that increase this risk is positive or negative news. E.g.; The exposure of a cryptocurrency exchange to a hacking attack or a negative news about the stock market may cause investors to fear losing all their money. This, in turn, creates selling pressure in the cryptocurrency market, affecting prices negatively. On the other hand, business partnerships or announcements of important developments in infrastructure by crypto projects will increase the faith and trust of the investors, which may create an upward momentum on the by cryptocurrency prices. Investors closely follow those and similar hot news as well as price performances about cryptocurrencies. Today, most information and news about cryptocurrencies are shared through digital channels and social media. In particular, people and institutions that analyse cryptocurrencies share the results of their analysis mainly on social media. Especially the younger generation has the advantage of being more active in crypto investments in the context of social media interaction experience. Social media channels are mostly followed by young people aged 18-34 across the world. (Hootsuite, 2021) Particularly, 28.9 percent of the user profile of Twitter, which is one of the channels where written and verbal information about crypto money is shared, is in the 23-34 age group. (Hootsuite, 2021) It can be said that the age group with the highest access to information about cryptocurrencies is young people in the light of these data.

\subsubsection{Gender}

Gender, one of the demographic features, is a phenomenon that individuals are born with and shapes the opportunities and threats that they may encounter throughout their lives. Different studies in the academic literature focus on the variability of investment decisions in the context of gender. Some studies have focused on the effect of gender on financial risk taking. For example, Fehr-Duda, de Gennaro and Schubert (2006) examined the relationship between gender, financial risk and probability weight in their studies and stated that women exhibit less risky behaviors than men. Considering other views on gender in the literature; Anbar and Eker (2009) stated that women are more cautious than men because they are more sensitive to violence, have maternal instincts and act more responsibly. Wang, Keller, and Siegrist (2011) concluded in their research on gender-based financial investment preferences that women see art, antiques and precious metal investments as alternative investments, and they see these investment alternatives as less risky compared to men. Women's passion for these alternatives affects their investment decisions. Uluyol (2019) conducted a study on academics. According to the results of this research, it was found that women tend to invest less in risky investment instruments, while men's income and savings level increase, such as stocks, housing, land, etc. stated that their preferences for immovables and precious metals (gold, silver) have increased.

\subsubsection{Education and Income Status}

It is known that the level of education affects the social environment of individuals and at the same time, individuals often act according to the social environment they are in. It is known that individuals with a high level of education make many analyses and examinations before making investment decisions in relation to their social environment and education level. (Usul et al., 2002). Income status of individual investors is one of the factors affecting investment decisions. As mentioned in the introduction, in order for individuals to invest, they must have income that can be directed to investment. Individuals with fixed or sustainable income can direct their savings to investment instruments more effectively. One of the factors affecting the fixed income of individuals is their educational status. Highly educated individuals can earn regular income as professionals. An individual with a low income and unable to save will not be able to invest, even if he or she has the desire to invest. (Aşıkoğlu, 1983) Alpay et al. (2015), in their study examining the effect of income level on other socio-economic and demographic factors that affect risk perception, found that the effects of gender, occupation and financial knowledge level factors on risk perception are strong for individuals with high income level. they detected. Since the income status of individual investors is influential on investment decisions, the low level of income associated with women's low participation in the labour force and economic production causes financial investments to be more limited. (ILO, 2019) The inability of women to take a sufficient place in working life and thus not earning income is one of the biggest barriers to investment. Although important policies are followed by international platforms and governments to increase the employment of female workforce, the role of women in the economy is still lower than men. According to 
the labour force statistics announced by the Turkish Statistical Institute (TUIK), 68.2 percent of men participate in the labour force, while this rate is 30.9 percent for women. According to TUIK data, the proportion of women between the ages of 1524 who are not in education or employment among the young population is approximately twice that of men. According to the World Economic Forum (WEF) Global Gender Gap report (2021), when the share of women in the workforce between 2014 and 2019 is examined, it is seen that their share has increased, but this rate has decreased sharply in both men and women in 2020. With the consequences of the crisis based on the workforce on a global scale due to Covid-19 and the pandemic, it was again against women. While the rate of men who lost their jobs was 3.9, the rate of women was $5 \%$. Within the framework of an inclusive sustainable economy and participation, it is possible to say that the disadvantaged position of women continues today and in the near future.

\subsection{Psychological Factors Affecting Cryptocurrency Investments}

In this section, the psychological factors affecting cryptocurrency investments will be discussed as perception, learning, motivation, emotions and stress.

\subsubsection{Perception}

Perception is to be aware of and evaluate the activities taking place around us with our sense organs (Karafakıoğlu, 2006). Factors affecting the level of perception; previous experience, level of knowledge, perception and ability to learn. (Ozer, 2009). Individuals with high perceptions in a particular area can make investment decisions faster, and the level of knowledge varies depending on the level of perception. The level of knowledge can be effective in cryptocurrency investments, which is a relatively new investment tool, as one of the factors that have an important effect on investment preferences. Among the sectors in which women are involved in employment, technology and related fields are the sectors with the widest gender gap. It can be said that women's level of knowledge and perceptions in the fields of blockchain technology and cryptocurrencies are low in parallel with their participation in the sector, which can be effective in investment decisions and preferences.

\subsubsection{Level of Knowledge}

Investor behaviour, like many other behaviors, can change through learning. Investors reflect the knowledge and experiences they have gained during their learning periods in life to their investment decisions (Tavşancı and Örücü, 2001). Financial information owned affects the decisions of investors. It is seen that women avoid risky investments due to the fact that women's financial knowledge level is generally lower than men. However, it is also seen that male investors with relatively high financial knowledge make erroneous financial decisions due to overconfidence. In addition to many traditional investment tools regarding cryptocurrency investments, this investment tool requires digital literacy. It is one of the important barriers to be able to understand and use this technology, which is effective in the analysis of cryptocurrencies produced on blockchain technology. Digital literacy requirements are most effective in cryptocurrency investments for the holding, storing and realization of the investment. Cryptocurrency investments that are traded in digital environments and stored in digital wallets must be carried out by the investor, especially due to security factors. The investor is responsible for all transactions in cryptocurrency investments, where all transactions are realized without intermediaries. For these reasons, individuals who invest in cryptocurrencies should have high digital literacy and learning capacity as well as financial literacy.

\subsubsection{Motivation}

The motivation of the individual investor is very effective in the decision process. People act according to their instincts for everything they need in life. (Celtek, 2004). It is seen that individuals with low motivation do not act sufficiently willingly and inquisitively in their investment decisions. Cryptocurrency trading requires close monitoring due to constantly changing prices, so an unmotivated investor may have low returns or even make a loss. The number of cryptocurrencies, which is a new investment tool, is increasing day by day. The requirement to do pre-investment research on each cryptocurrency that offers different value propositions can be challenging for many investors. As can be seen in the detailed information about the cryptocurrency market in the previous section, the number of cryptocurrencies above 10 thousand is a very high number for individuals with low motivation to research and follow. In this research focus, the subject of individual motivation can be considered as a psychological factor that is especially effective in cryptocurrency investments.

\subsubsection{Emotions and Stress}

Emotions can be basically listed as joy, anger, interest, disgust, surprise, sadness and fear. Each of these emotions can have different effects on investor behaviour. In addition, changes in stress level will also affect investor behaviour. Stressed individuals may not be able to make rational decisions in case of possible financial loss and may deepen their financial losses. Cryptocurrency investments, like other traditional investment tools, can be affected by emotions and stress. Rapid price changes can be an important source of stress, especially in cryptocurrency investments with high price volatility. One of the most important factors affecting the prices of cryptocurrencies is the supply and demand situation. The supply and 
demand amounts of cryptocurrencies are an important indicator in measuring the level of interest in cryptocurrencies. Since traditional currencies are under the control of the government and Central Banks, they are printed and put on the market whenever they want. The supply of cryptocurrencies is limited. (Deniz, 2020) It is likely that the prices of cryptocurrencies, which are produced in small quantities and with limited supply, will increase. As the interest in cryptocurrencies increases and the demand to buy increases, the prices of cryptocurrencies are on the rise. The increase in demand, in turn, causes a decrease in the amount of cryptocurrencies circulating in the market and therefore a decrease in the supply level. On the other hand, it is seen that the prices of cryptocurrencies decrease as the sales decisions and the amount of circulation in the market increase. The value of the cryptocurrency, which becomes easily accessible in the market by increasing its supply, may decrease. Similarly, the necessity of managing the cryptocurrency investment process by the individual investor can often cause emotional difficulties for individuals who complete their investment processes with intermediaries. Cryptocurrency investments made entirely in the digital environment and using technology carry different sources of stress, including security.

\section{DATA AND METHODOLOGY}

In this quantitative research on the examination of the factors affecting cryptocurrency investments in the context of gender, the screening model was used as a method. Data were collected from 399 participants through a computer-assisted survey. The questionnaire questions applied in this study were included in the literature section, and the demographic factors affecting the investment decisions of individuals such as age, gender, income status, marital status, and educational status, and psychological factors such as perception, learning, motivation, emotions, and stress were included. The survey study starts with questions to measure the demographic information of the participants and their level of knowledge about cryptocurrencies, and continues with questions about the analysis of investment preferences. There are a total of 21 questions in the survey, and the survey questions were created through Google Forms. The survey link was sent to the participants via different social media accounts on the internet, and no personal information (name, surname, e-mail address, telephone, etc.) was requested for the accuracy of the study results, taking into account the participants' reservations about answering. The questionnaire was directed to male and female participants simultaneously, and the results were analysed on a gender basis. The survey study applied to the sample of Turkey was carried out between 23-30 August 2021.

Based on the demographic factors that affect the investment decisions of individuals mentioned in the previous sections, the basic data about the participants of the research survey applied are as follows:

- $\quad$ Gender: $57.6 \%$ of the participants are female; 42.4 percent are men.

- Marital Status: 66.7 percent of the participants are married; 33.3 percent of them are single.

- Income status: 86 percent of the participants are actively working. The percentage of participants who own their own house is 49.6 .

- $\quad$ Educational Status: While 7 percent of the participants have a high school education level or below, 93 percent have a bachelor's degree or higher.

- Age: The age distribution of the participants was broken down as 20-30, 30-40, 40-50, and 50 and over, respectively, and the distribution of the research participants by age breakdown is shown in Table 2 .

Table 2: Distribution of Research Participants by Age Breakdown

\begin{tabular}{ccccc}
\hline & $\mathbf{2 0} \mathbf{- 3 0}$ & $\mathbf{3 0 - 4 0}$ & $\mathbf{4 0 - 5 0}$ & $\mathbf{5 0}$ and above \\
\hline Woman & 33 & 119 & 58 & 20 \\
Man & 30 & 87 & 40 & 12 \\
Total & 63 & 206 & 98 & 32 \\
\hline
\end{tabular}

The participants of the survey consist of men and women in a close percentage. Cryptocurrency is included in the investment portfolios of 27 percent of the total participants. These basic demographic data show that the research sample is in an appropriate distribution according to the factors affecting the investments.

\section{FINDINGS AND DISCUSSION}

\subsection{Findings Related to Psychological Factors}

Cryptocurrency is included in the investment portfolios of the research participants. Considering the number of participants investing in cryptocurrencies by gender, shown in Table 3, 32.6\% of women and 53.2\% of men invest in cryptocurrencies. 
Table 3: Distribution of Research Participants by Cryptocurrency Investments

\begin{tabular}{lcc}
\hline & Woman & Man \\
\hline Total number of participants & 230 & 169 \\
Number of participants investing in cryptocurrencies & 75 & 90 \\
\hline
\end{tabular}

Based on the findings, it is seen that men include more cryptocurrencies in their investment portfolios. Figure 4 shows the preference rates of instruments and cryptocurrencies in investment portfolios based on gender.

Figure 4: Investors' Investment Instrument Preference Chart

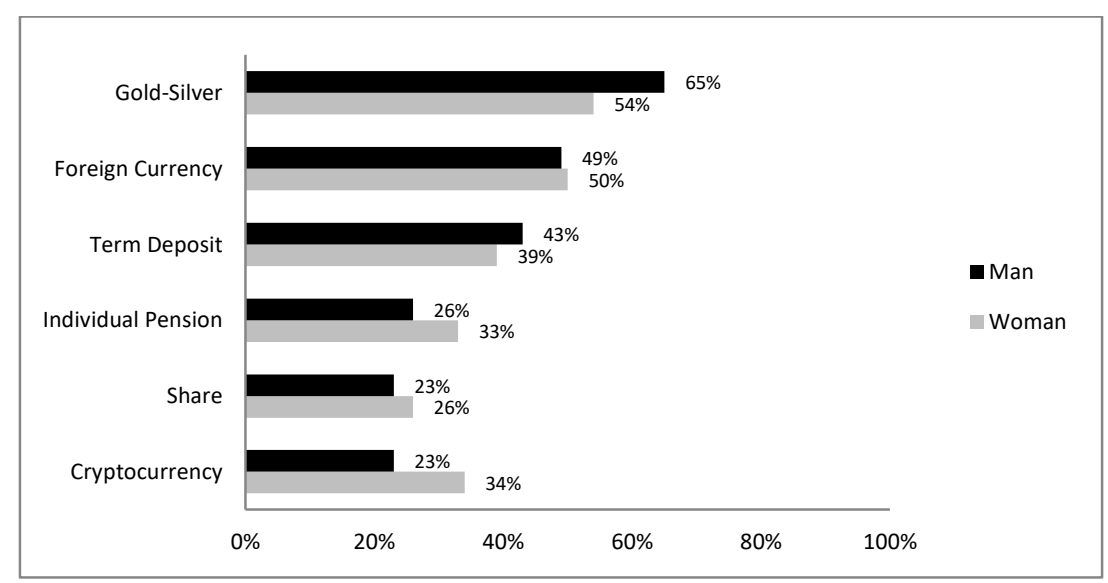

When the survey results related to the study are examined, the percentage distributions of 109 participants who prefer cryptocurrencies in their investment portfolios based on age ranges are given in Table 4. While it is observed that 74.3 percent of the total investors are between the ages of 20-40, it is observed that the age breakdown by gender is similar. It is seen that female investors between the ages of 20-40, which we can consider as young and middle-aged, have a high share of 73.1 percent. It is observed from the survey findings that among female investors, cryptocurrencies are mostly preferred by the young and middle-aged groups, and that those who are older are more distant to cryptocurrencies. This finding is compatible with the literature.

Table 4: Age Distribution Percentages of Cryptocurrency Investors

\begin{tabular}{lcccc}
\hline & $\mathbf{2 0 - 3 0}$ & $\mathbf{3 0 -} \mathbf{4 0}$ & $\mathbf{4 0 - 5 0}$ & $\mathbf{5 0}$ and above \\
\hline Woman & $15.4 \%$ & $57.7 \%$ & $25 \%$ & $1.9 \%$ \\
Man & $22.8 \%$ & $52.6 \%$ & $21.1 \%$ & $3.5 \%$ \\
Total & $19.3 \%$ & $55 \%$ & $22.9 \%$ & $2.8 \%$ \\
\hline
\end{tabular}

Another demographic factor that affects investment decisions is income. Information on the effects of individual investors' income levels on their investment decisions has been shared in detail in the literature section. When the income status is analysed according to the survey data, employment status and home ownership data, it is seen that it is in parallel with the cryptocurrency investments. When the survey results are read on the basis of household income, it is seen that as the income of individuals increases, their monthly savings opportunities increase. The distribution of the research participants by household income is shown in Table 5. If we look at the relationship between household income and cryptocurrency trading experience; While 37.8 percent of those with a monthly household income between 0-5,000 TL have traded cryptocurrencies before, 45.9 percent of those with a household income of 20,000 TL or more declared that they had previously traded cryptocurrencies. It is observed that individuals with higher monthly incomes invest in cryptocurrencies more for a part of their savings, compared to individuals with low income.

Table 5: Distribution of Participants by Household Income

\begin{tabular}{lcccc}
\hline $\begin{array}{l}\text { Household income } \\
\text { (TL) }\end{array}$ & $\mathbf{0 - 5 0 0 0}$ & $\mathbf{5 0 0 0 - \mathbf { 1 0 0 0 0 }}$ & $\mathbf{1 0 0 0 0 - \mathbf { 1 5 0 0 0 }}$ & $\mathbf{2 0 0 0 0}$ and above \\
\hline Participants & $11.3 \%$ & $32.6 \%$ & $31.6 \%$ & $24.6 \%$ \\
\hline
\end{tabular}


When we look at the gender breakdown of the research participants who are not actively working, 78 percent of the women are not working. Depending on the finding of cryptocurrency investment preference increasing in parallel with income, it can be said that one of the main factors in the low rate of female investors is income. According to Hicks' (1946) approach, income in the context of the individual investor can be defined as the highest amount that can be consumed in a given time period and at the end of that time period, the initial level of welfare can be maintained. (Procházka, 2009) Labour force participation rate is an important economic indicator found with the ratio of the total workforce to the working population. Based on the survey findings in the focus of crypto money investments, the rate of female investors, which is low, can be predicted to continue in this course depending on this information.

\subsection{Findings Related to Psychological Factors}

Among the research findings, perception and learning, which are the psychological factors affecting cryptocurrency investments, were examined through the level of knowledge. Motivation, emotions and stress factors, which are other psychological factors, were examined through the investment experiences of the participants and discussed mainly on the risk factor and rationality. Findings related to psychological factors affecting cryptocurrency investments under both main headings are presented with gender-based data and discussed in this section.

Cryptocurrency, which is a relatively new investment tool, requires digital literacy as well as financial literacy compared to many other investment tools. One of the important factors affecting the motivation to invest in cryptocurrencies, which is an investment tool with high volatility, is the level of knowledge. One of the most gender-related differences in cryptocurrency investments is the level of knowledge. According to the research data, 11.5 percent of the participants think that they do not have enough information about cryptocurrencies. 56 percent of women have never heard of cryptocurrencies or have very limited knowledge about cryptocurrencies. The level of knowledge of female and male participants about cryptocurrencies is shown in detail in Figure 5. The level of knowledge, which is lower than that of men, stands out as an important factor in investment decisions. It is one of the research findings that the sources of information related to knowledge ownership do not differ depending on gender. From the answers to the questions asked about the knowledge of the details of the investment instruments in the cryptocurrency market, it is seen that there is no genderrelated differentiation. The top five cryptocurrencies that crypto investors have heard of do not show gender-related variability.

Figure 5: Level of Knowledge about Cryptocurrencies

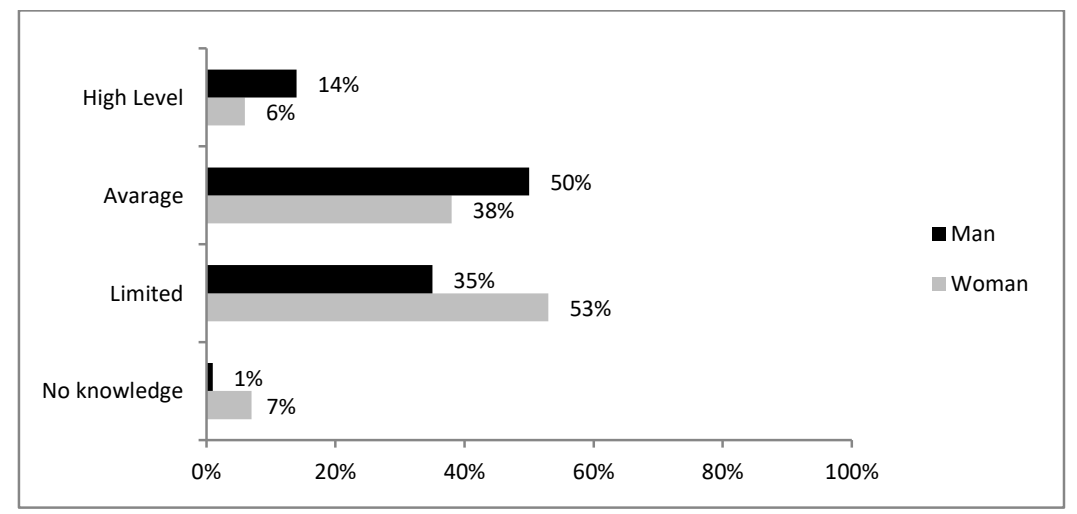

According to the research findings, cryptocurrency investment motivation is parallel to the knowledge on this financial instrument. Based on this finding, which is compatible with the literature that one of the important psychological factors affecting cryptocurrency investments is the level of knowledge, the rate of participants who invest in cryptocurrencies is 33 percent for women and 53 percent for men.

Although cryptocurrencies are among the top 6 investment instruments most preferred by the survey participants, their ranking within the investment portfolio varies depending on gender. When we look at the investment preferences shown in detail in Figure 4 in line with the preferences of female investors, cryptocurrency investments are at the sixth place where cryptocurrencies are among the top 5 of male investors. Based on the survey findings, we can say that men prefer cryptocurrencies more than women in their investments. Looking at the breakdown of the research participants according to their cryptocurrency investments, shown in Table 3, it is seen that men invest in cryptocurrencies, which is a relatively risky tool compared to other investment tools, more than women. Therefore, it is confirmed that the tendency to take risks is higher than that of women. Many studies examining the investment decisions of investors in the context of gender show that women's risk-taking tendencies are different from men's and they are more cautious than men. (Baltaş, 2021) Considering other views on gender in the literature; Anbar and Eker (2009) stated that women are more cautious than men because they are more sensitive to violence, have maternal instincts and act more responsibly. Uluyol (2019) stated that 
women are less inclined towards risky investment instruments. Some studies have focused on the effect of gender on financial risk taking. For example, in the study of Fehr-Duda et al. (2006), it is stated that women exhibit less risky behaviors and control more than men. Although the effect of the risk factor related to gender in cryptocurrency investments, which is compatible with the literature, is observed in these research findings, the proportional difference based on gender is observed to be low. The risk of loss is observed in the research findings as one of the primary factors affecting the investment decision of women. Again, in connection with the risk factor, factors such as trust and reliability are among the first three factors that affect investment decisions. The data of this research on rationality, which is one of the psychological factors in investment decisions, shows that both men and women state that men are more rational, with a low proportional difference. The dynamics of the cryptocurrency market and the volatility of crypto prices bring the need for regular followup and short-term investment changes in this investment tool. Based on the survey findings, 70 percent of female investors and 80 percent of men declared that they constantly follow their investments. It can be said that risk factor as a psychological factor and the necessity of follow-up are among the reasons why it is an investment tool that is preferred by female investors at a low rate. Considering the factors that affect the investment decisions of individual investors, it is observed that the factors of reliability and return are most effective. Risk of loss, easy conversion to cash and economic indicators in the country are also among the top 5 considerations, while the protection of the principal and investor comments are also noted, with a lower rate among the considerations. When the first 5 of the factors affecting the decisions of individual investors are analysed by gender, it is observed that the most differentiated ones are in the factors of easy cash conversion and economic indicators in the country. As can be seen in detail in Figure 6, the economic indicators factor in the country, which is among the factors that show a proportional difference depending on gender taken into account in investment preferences, is accounted for by 41 percent of women and 49 percent of men, and the easy conversion factor into cash by 40 percent of women and 49 percent of men.

Figure 6: Factors Affecting Investment Decisions

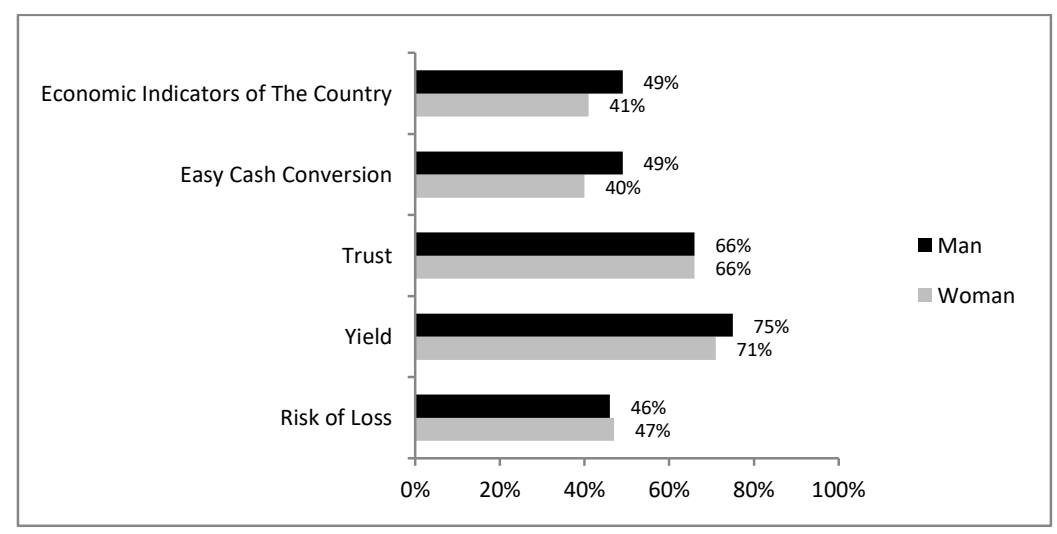

Similarly, when the factors affecting investment decisions are examined within the framework of cryptocurrency investments, the first 5 factors among the survey findings are trust (trust in the trading platform), volatility (extreme price mobility), regulations, blockchain technology, and commission. Although the first two factors do not differ according to gender, their rankings are different depending on their percentages. While the two most important factors are confidence with 49 percent in women and volatility in the second place with 34 percent, while volatility is in the first place with a high rate of 57 percent in men, while the element of confidence is in the second place with a rate of 49 percent.

\section{CONCLUSION}

Investors always think that they are rational and make the right decision while investing. However, many studies in the literature have shown that investors do not act rationally. The understanding of behavioral finance is a large research area in which studies on this subject are made. Investment decisions are affected by many demographic and psychological factors. One of the important factors affecting investment decisions is gender. In this research, the examination of the factors affecting investment decisions regarding cryptocurrencies, one of the investment instruments, in the context of gender reveals the relationship between gender and both psychological and demographic factors. When the results of the survey conducted within the scope of the study are compared with similar studies on traditional investment instruments in the literature, it is seen that women prefer different investment tools primarily due to their lower knowledge level and lower income level, especially in cryptocurrency investments. While gold and silver as an investment tool ranks first among the investment products most preferred by both women and men, cryptocurrency investments, which are among the top five for men, are not among the top five in women's preferences. The rate of female participants choosing cryptocurrencies in their investment preferences is 20 percent lower than that of male investors. Cryptocurrencies are seen as a risky investment tool for both men and women due to their extremely volatile price structure. In cryptocurrencies, where prices are so volatile, continuous monitoring is important in terms of the risk of loss. In this context, another result obtained from 
the study is that men follow their investments more frequently than women. Another finding obtained from the study is that the age group that prefers cryptocurrencies for both male and female participants is the middle age group. The fact that cryptocurrencies require digital literacy in addition to financial literacy compared to other investment tools and that the information flow is predominantly through digital media channels shows that it is an investment instrument mostly preferred by young people. Cryptocurrency, which is an investment tool preferred by female investors aged 20-40, which we can consider as young and middle age, shows similarity in age-related preference by male investors. Women's labor force participation and low incomes cause them to direct their investment preferences to less risky products. The gender gap in employment in the context of a sustainable economy is clearly reflected in the gender-related differentiation of cryptocurrency investment preferences. Due to the fact that the survey participants are not homogeneously distributed in terms of education level, research findings on the effect of education on cryptocurrency investments are not included. It has been seen that the findings obtained as a result of the study are in parallel with the literature on traditional financial investment instruments. The research makes an important contribution to the relevant literature as one of the first studies in the context of gender within the framework of cryptocurrency investments.

\section{REFERENCES}

Alpay, E., Yavuz, M. \& Kahyaoğlu, M. (2015). The effect of income status on other socio-economic and demographic factors affecting risk perception. Cumhuriyet University Journal of Economics and Administrative Sciences, 16 (1), 205-226.

Anbar, A., \& Eker, M. (2009). Demographic and socioeconomic factors affecting individual investors' perceptions of financial risk. International Journal of Management, Economics and Business, 5 (9), 129-150.

Ağıkoglu, R. (1983). Valuation of Bonds in Inflation Environment as a Capital Market Instrument. Anadolu University Publications, No.35.

Baltaş, A. (2021). The Effect of Gender on Financial Decisions. https://www.acarbaltas.com/ [ Access date: 12.05.2021 ]

CoinGecko (2021). https://www.coinecko.com/tr [ Accessed on:04.10.2021 ]

CoinMarketCap (2021). https://coinmarketcap.com/ [ Accessed on:04.10.2021]

Çeltek, E. (2004). Motivation management. Journal of Industrial Relations and Human Resources, 6 (1), 1-15.

Deniz, E.A. (2020). Cryptocurrency Applications in Financial Markets: Factors Affecting Cryptocurrency Prices. Master's Thesis. Işık University Institute of Social Sciences. İstanbul.

Doğan, S. (2020). The transformation of money in the digital age: cryptocurrencies and blockchain technology: a study for university students. Anemon Mus Alparslan University Journal of Social Sciences, 8 (3), 859-870.

Ecom World. (2021). Kripto paralar neden gerçek para birimleri sayılmıyor https://ecomworld.net/2021/05/26/kripto-paralar-ve-paraningeleneksel-fonksiyonlari/ [ Access date: 22.08.2021]

Fehr-Duda, H., de Gennaro, M. \& Schubert, R. (2006) Gender, Financial Risk, and Probability Weights. Theory of Decision, 60, 283313. https://doi.org/10.1007/s11238-005-4590-0

Google Trends (2021). Cryptocurrency. https://trends.google.com/trends/explore?date=2009-0101\%2020211008\&q=\%2Fm\%2F0vpj4_b [Accessed on:09.10.2021]

Gül Şenkardes, C. (2021) Blockchain technology and NFTS: a review on the music industry. Journal of Management, Marketing and Logistics, 8 (3), 154-163.

Gulec, O. F., Çevik, E., \& Bahadır, N. (2018). Examining the relationship between bitcoin and financial indicators. Kırklareli University Faculty of Economics and Administrative Sciences Journal, 7 (2), 18-37.

Güleç, T.C., \& Aktaş, H. (2014). Analysis of efficiency in cryptocurrency markets by testing long memory and varying variance properties. Journal of Eskişehir Osmangazi University Faculty of Economics and Administrative Sciences, 14 (2), $491-510$.

Hallahan, T.A., Faff, R.W., \& McKenzie, M.D. (2004). An empirical investigation of personal financial risk tolerance. Financial Services Review, 13, 57-78.

Hootsuite (2021). Digital 2021 Global Statshot Report. https://www.hoosuite.com/pages/digital-trends-2021 [ Accessed on 17.10 .2021 ]

ILO (2021) World Employment and Social Outlook: Trends 2021. https://www.ilo.org/wcmsp5/ groups/public/---dgreports/---dcomm/--publ/documents/publication/wcms_795453. pdf [Accessed 12.09.2021]

Jones, C.P. (1994), Investments Analysis and Management. 4th edition, John Wiley \& Sons.

Kahyaoğlu, M.B. (2011). The role of gender on the level of exposure to various emotional and psychological factors affecting investment decisions: an application on ISE individual stock investors. Journal of Economic and Social Research, 7(1), 7:29-51 29.

Karafakioğlu, M. (2006). Marketing Principles. Istanbul: Literature Publishing.

Korniotis, G.M. \& Kumar, A. (2011). Do older investors make better investment decisions? The Review of Economics and Statistics, 93 (1), 244-265. 
Nakamoto, S. (2008). Bitcoin: a peer-to-peer electronic cash system. https://bitcoin.org/ bitcoin.pdf [Accessed on 16.09.2021]

Özdaş, Y. (2009). Investment Incentives Applied in Turkey and A Study in Diyarbakir Region. (Unpublished Master's Thesis) Adana: Çukurova University $\mathrm{MoH}$ Institute.

Özer, N. (2009). Detection and marketing applications. Paradox - Journal of Economics, Sociology and Politics (1), 1-12.

Pelster, M., Breitmayer, B. \& Hasso, T. (2019). Are cryptocurrency traders' pioneers or just risk-seekers? evidence from brokerage accounts. Economics Letters, 182, 98-100.

Procházka, D. (2009). The Hicks' Concept of income and its relevancy for accounting purposes. European Financial and Accounting Journal. 4. 37-60. 10.18267/j.efaj.62.

Statista, (2021) Estimate of overall cryptocurrency market cap per week. https://www.statista.com/statistics/730876/cryptocurrencymaket-value/ [Accessed on 19.09.2021]

Sütçü, C.S. \& Aytekin, C. (2018, July). A study on entrepreneurship levels of social media users related to bitcoin and crypto money. The Turkish Online Journal Of Design, Art And Communication, 8 (3), 466-488.

Tavşancı, S. \& Knitter, E. (2001). Factors affecting consumer's purchasing tendency in food products and packaging. Journal of Muğla University Institute of Social Sciences (3).

CBRT (2021). Financial Accounts Report, 2021. 1. Quarter.

https://www.tcmb.gov.tr/wps/wcm/connect/TR/TCMB+TR/Main+Menu/Yayinlar/Raporlar/Finansal+Hesaplar+Raporu/ [Accessed on: 12.09.2021]

TUIK (2021). Turkish Statistical Institute. Statistics Data

Portal. https://data.tuik.gov.tr/Search/Search?text=\%C4\%B0\%C5\%9Fg\%C3\%BCc\%C3\%BCne\%20Kat\%C4\%B1|\%C4\%B1m\%200ran\%C4\%B1 [A ccessed on:29.08.2021

Uluyol, O. (2019). Investigation of academicians' recognition of investment instruments and investing in these instruments: Turkey practice. Research Studies Aanatolia Journal, 2 (4),1-20.

Usul, H., Bekçi, i. \& Eroğlu, A.H. (2002). Socio-economic factors affecting individual investors' acquisition of stocks. Journal of Erciyes University Faculty of Economics and Administrative Sciences (19), July-December, 135-150.

Ülgen, K. (2010). Electronic Money: Turkey and the World Application. Master's Thesis, Inönü University, Institute of Social Sciences, Department of Economics, Malatya.

Wang, M., Keller, C. \& Siegrist, M. (2011). The less you know, the more you are afraid of - a survey on risk perceptions of investment products, Journal of Behavioral Finance , 12:1, 9-19, doi: 10.1080/15427560.2011.548760

Yılmaz, F. \& Akkaya, G.C. (2020). Efficiency in cryptocurrency markets; day of the week effect: the case of bitcoin and litecoin. Journal of Entrepreneurship, Innovation and Marketing Research, 4 (8), 166-178.

Yılmaz, N. (2009). The Relationship Between Factors Affecting Investor Behavior and Investment Decisions. Individual-Institutional Investor Differentiation. Master Thesis. Yıldız Technical University.

Yilmaz, N. K., Hazar, H. (2018). Determining the factors affecting investors' decision-making process in cryptocurrency investments. PressAcademia Procedia (PAP), V.8, p.5-8.

Yılmaz, Y. (2007). Legal dimension in cryptology applications. Marmara University Faculty of Law Journal of Legal Studies, 13 (1-2), $137-147$. 